\title{
Characterization of synovium-derived mesenchymal stem cells from joints with osteochondritis dissecans
}

\author{
Shama Rao ${ }^{1}$, Siddharth Shetty ${ }^{2}$, Narendra Nitilapura ${ }^{1}$, Veena Shetty ${ }^{1}$, Guruprasad Kanive Parashiva ${ }^{3}$, \\ Mohana Kumar Basavarajappa ${ }^{1, *}$
}

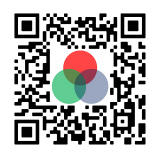

Use your smartphone to scan this QR code and download this article

${ }^{1}$ Nitte University Center for Stem Cell Research and Regenerative Medicine, $K$. S. Hegde Medical Academy, Nitte (Deemed to be University), Deralakatte-575018, Mangaluru, India

${ }^{2}$ Department of Orthopaedics, K. S. Hegde Medical Academy, Nitte (Deemed to be University), Deralakatte-575018, Mangaluru, India

${ }^{3}$ School of Life Sciences, Manipal Academy of Higher Education, Madhav Nagar, Manipal-576104, India

Correspondence

Mohana Kumar Basavarajappa, Nitte University Center for Stem Cell Research and Regenerative Medicine, K. S. Hegde Medical Academy, Nitte (Deemed to be University), Deralakatte-575018, Mangaluru, India

Email:mohanakumar@niite.edu.in

History

- Received: Aug 13, 2020

- Accepted: Oct 15, 2020

- Published: Oct 31, 2020

DOI : 10.15419/bmrat.v7i10.645

\section{Check for updates}

Copyright

(๑) Biomedpress. This is an openaccess article distributed under the terms of the Creative Commons Attribution 4.0 International license.

\begin{abstract}
Introduction: Osteochondritis dissecans (OCD) is a pathologic condition that occurs in children as well as adults. OCD is often managed based on the extent of ischemia and the stage of the disease. Synovial tissue collected during an arthroscopic procedure might serve as an ideal source for autologous mesenchymal stem cells (MSCs) with a potential for regenerative medicine of cartilage. Therefore, the present in vitro study aimed to evaluate the potency characteristics of synovium-derived MSCs (SMSCs) from joints with OCD for prospective autologous therapy. Methods: Primary culture of SMSCs was established and basic cellular properties, such as morphology, growth kinetics and clonal propagation ability, were analyzed. The expression of phenotypic markers, including CD29, CD44, CD90, CD34 and CD45, was assessed by flow cytometry and immunocytochemistry. Mesodermal differentiation into osteocytes, chondrocytes and adipocytes was performed using standard protocols. Expression of chondrocyte-specific markers was analyzed by reverse transcriptase-polymerase chain reaction (RT-PCR). Results: Isolated SMSCs displayed fibroblast-like morphology with $>95 \%$ cell viability and had high proliferative rates with a shorter doubling time. The cells showed positive expression of CD29, CD44 and CD90, but were negative for CD34 and CD45 markers. Upon induction, SMSCs were successfully differentiated into osteogenic, chondrogenic and adipogenic lineages. Chondrogenesis was more prominent in SMSCs than osteogenesis. Chondrogenesis was further confirmed by the expression of aggrecan and collagen type $\| \alpha 1$ markers. Conclusion: SMSCs showed greater proliferation and an enhanced ability for chondrogenic differentiation. Synovium can be harvested with minimal tissue damage and donor-site morbidity and might serve as an alternative autologous source of MSCs for cartilagetissue regeneration.
\end{abstract}

Key words: Synovial-derived MSCs, Potency, Differentiation, Osteochondritis dissecans

\section{INTRODUCTION}

Osteochondritis dissecans (OCD) is a condition due to ischemic insult to the subchondral bone, resulting in damage to hyaline cartilage of the joint and leading to separation of the bone and the overlying cartilage; it affects both children and adults ${ }^{1,2}$. In OCD, the bone and cartilage break loose, causing pain and hindering joint motion. Its etiology is still unexplained. The most commonly affected joints are the knee, ankle and elbow ${ }^{3}$. The condition, if untreated, can progress to uneven joint surfaces, leading to the defects being replaced by fibrous cartilage and progressing to osteoarthritis ${ }^{4}$. OCD is often managed based on the extent of ischemia and the stage of separation from the underlying bone, and surgery is performed to replace the fragment and fix it with implants ${ }^{5}$. This procedure may not be successful in all cases. Hence, cartilage transplant and cartilage grafting could be a promising procedure. In joints, naturally existing mesenchymal stem cells (MSCs) can be found in both synovial and solid joints as well as the ligaments of the mammalian body. Human synovial-derived MSCs (SMSCs) were first described by De Bari et al., when they successfully isolated them in $2001^{6}$. MSCs have also been isolated and characterized from the meniscus, ligaments, fat pad, and cartilage of the joints, suggesting that MSCs play a crucial role in the maintenance and function of these tissues ${ }^{7}$.

Several studies have shown that MSCs are involved in the maintenance and regeneration of connective tissues, and are known to migrate to tissues as a result of injury or inflammation, where they participate in the repair of damage ${ }^{7-9}$. Indeed, a recent case series report provided an option for treating juvenile OCD using human umbilical cord blood-derived mesenchymal stem cells (hUCB-MSCs) ${ }^{10}$. Further, a study on rats with articular cartilage defects demonstrated that SMSCs were able to differentiate into cartilaginous cells depending on the microenvironment ${ }^{11}$. Synovial tissues, as source of MSCs, may be preferable for 
transplantation as well as cell-banking purposes, and investigations in this regard are scanty ${ }^{7,12,13}$. However, studies report the consideration of SMSCs as a promising alternative; it is still critical to examine whether autologous SMSCs reside in the joints of OCD patients. Therefore, the aim of this in vitro study herein was to isolate SMSCs from joints with OCD, and to characterize them in terms of morphology, growth kinetics, clonal propagation ability, expression of MSC-specific positive (CD29, CD44, and CD90) and negative (CD34 and CD45) markers, and potential for osteogenic, chondrogenic and adipogenic differentiation. The findings have provided evidence to utilize the synovium as a potential autologous source of MSCs for cartilage regeneration.

\section{MATERIALS - METHODS}

\section{Collection of synovial tissue}

The study obtained prior permission from the Institutional Ethics Committee (No. NU/CEC/2017/0182) and Institutional Committee for Stem Cell Research (No. NU/ICSCR/2016-17/002A/P10) (Mangaluru, India). A total of five samples of human synovial membrane were collected, and three cell lines were selected for performing qualitative and quantitative analysis using various cell-based assays ${ }^{6}$. The samples were obtained from male patients undergoing knee arthroscopy surgery for OCD with cartilage damage (age range: 35 to 45 years; mean age: 39.25 years). Informed consent was obtained for all patients and was a requisite for the treatment procedure. Patients with rheumatoid arthritis were excluded. The procedure was performed under anesthesia, and the synovium was harvested from the suprapatellar pouch using arthroscopic basket forceps or a suction rotatory aspirator device.

\section{Chemicals and media}

All chemicals were purchased from Sigma Chemical Company (St. Louis, MO), media from Thermo Fisher Scientific (Gibco-Invitrogen, Life Technologies, MA), and cell culture plastic wares from Thermo Fisher Scientific, unless otherwise specified.

\section{Isolation of synovium-derived mesenchy- mal stem cells (SMSCs)}

Isolation of SMSCs was performed according to the protocol described by De Bari et al. ${ }^{6}$, with minor modifications. Briefly, the collected samples were washed 3-4 times thoroughly with Dulbecco's phosphate buffered saline (DPBS) and minced into small pieces. Then, they were treated with $0.05 \mu \mathrm{g} / \mathrm{mL}$ type
II collagenase enzyme in Dulbecco's modified essential medium (DMEM) at $37^{\circ} \mathrm{C}$ overnight. From the cell suspension, enzyme was removed by centrifugation and was plated in DMEM supplemented with $10 \%$ fetal bovine serum (FBS), $100 \mathrm{U} / \mathrm{mL}$ penicillin, and $100 \mathrm{U} / \mathrm{mL}$ streptomycin until cells reached 80 $90 \%$ confluence for trypsinization. The cells were cultured at $37^{\circ} \mathrm{C}$ with $95 \%$ humidity and $5 \% \mathrm{CO}_{2}$. Seeding density for primary culture was 8000 cells $/ \mathrm{cm}^{2}$, while sub-passage seeding density was maintained at approximately $3000-3500$ cells $/ \mathrm{cm}^{2}$. Out of five synovial membranes collected, SMSCs were successfully established and cultured in four samples. For analyses, three cell lines from passage 2 (P2) to passage 5 (P5) were used, and all experiments were carried out at least in triplicate.

\section{Partial clonal propagation of SMSCs}

SMSCs (50 cells/dish) were cultured in $100-\mathrm{cm}^{2}$ cell culture dish using a partial clonal population technique as described previously ${ }^{14}$. Culture media was changed every 3 days. Once the colonies reached more than 25 cells, they were harvested and further sub-passaged for experiments.

\section{Viability assay}

Cell viability at P0 to P4 were performed by trypan blue exclusion test with a hemocytometer.

\section{Proliferation rate and population doubling time (PDT)}

SMSCs were plated at 10,000 cells/well in 12-well plates and cultured for 12 days. Cells were harvested with $0.25 \%$ trypsin-EDTA on the $3^{r d}, 6^{t h}, 9^{\text {th }}$ and $12^{\text {th }}$ day after seeding, and counted using a hemocytometer. The culture medium was changed every 3 days. The experiment was performed in triplicate and the proliferation rate was calculated. Population doubling time (PDT) was calculated using the formula: $\mathrm{PDT}=\mathrm{t}(\log 2) /(\log \mathrm{Nt}-\log \mathrm{No})$, where $\mathrm{t}$ represents culture time; No: initial cell number; Nt: final cell number.

\section{Colony-forming assay}

Isolated SMSCs were cultured with an initial cell density of 50 cells $/ \mathrm{cm}^{2}$. Fresh culture media was added twice weekly. After 14 days of culture, cells were stained with $1 \%$ Crystal violet solution and colonies were observed under phase-contrast microscope (Olympus, Tokyo, Japan). 


\section{Flow cytometry analysis}

SMSCs at $80 \%$ confluence were trypsinized and fixed with $3.7 \%$ paraformaldehyde for $30 \mathrm{~min}$. Cells were resuspended in $50 \mu \mathrm{L}$ cell-staining buffer (Biolegend, CA, USA) and incubated with antibodies, such as CD29 (eBioscience, CA, USA, 1:100), CD44 (Biolegend, 1:100), CD90 (eBioscience, 1:100), CD34 (Biolegend, 1:100) and CD45 (eBioscience, 1:100), for $4 \mathrm{hrs}$ at $4^{\circ} \mathrm{C}$. Then, cells were incubated in fluorescein isothiocyanate (FITC)-conjugated anti-mouse IgG (eBioscience, 1:100) secondary antibody for $1 \mathrm{hr}$ at room temperature. As an isotype control, mouse immunoglobulin G (eBioscience) was used. Cell fluorescence was acquired by fluorescence-activated cellsorting (FACS) (BD FACSCalibur, Becton Dickinson) and data was analyzed using Cell Quest software (Becton Dickinson).

\section{Immunocytochemistry analysis}

SMSCs were sub-cultured into four-chambered imaging slides (Eppendorf, Hamburg, Germany) until confluent and then fixed in $3.7 \%$ paraformaldehyde for $30 \mathrm{~min}$. Nonspecific sites of the cell membrane were blocked using $1 \%$ bovine serum albumin (BSA) for $1 \mathrm{hr}$ at room temperature. Cells were incubated with the aforementioned primary antibodies at $4{ }^{0} \mathrm{C}$ for overnight followed by secondary antibody at 37 ${ }^{0} \mathrm{C}$ for $1 \mathrm{hr}$. Then, the cells were counter-stained with propidium iodide (PI) for $5 \mathrm{~min}$ at room temperature. Finally, the slides were mounted for observation under a fluorescent microscope (Olympus, Tokyo, Japan).

\section{Multi-lineage differentiation potential}

The ability of the SMSCs to undergo in vitro differentiation into osteocytes, chondrocytes and adipocytes were evaluated after 3 weeks of culture in specific medium. To assess osteogenic differentiation, SMSCs were cultured in DMEM containing $100 \mu \mathrm{M}$ dexamethasone, $0.01 \mathrm{M} \beta$-glycerophosphate and $50 \mathrm{mg} / \mathrm{mL}$ ascorbate-2-phosphate. Following this, the cells were assayed for calcium deposition using von Kossa staining method. To assess chondrogenic differentiation, SMSCs were cultured in DMEM supplemented with $1 \%$ ITS mix (10 mg/L insulin, $5 \mathrm{mg} / \mathrm{L}$ transferrin, and $5 \mu \mathrm{g} / \mathrm{L}$ selenium), $0.1 \mu \mathrm{M}$ dexamethasone, 1 $\mu \mathrm{M}$ ascorbate-2-phosphate, and $5 \mathrm{ng} / \mathrm{mL}$ transforming growth factor-beta3 (TGF- $\beta 3$; Peprotech, NJ). After 3 weeks of culturing SMSCs, cells were stained with Alcian blue for the confirmation of deposition of glycosaminoglycans and proteoglycan synthesis. For adipogenic differentiation, SMSCs were cultured in adipogenic induction medium containing $100 \mathrm{nM}$ dexamethasone, $0.5 \mathrm{mM}$ isobutyl-methylxanthine, 10 $\mathrm{mM}$ indomethacin, and $10 \mu \mathrm{g} / \mathrm{mL}$ insulin. To determine the potency of the responding cells for adipogenesis, the cells were stained with Oil Red O solution.

\section{Reverse transcription- polymerase chain re- action (RT-PCR)}

The expression of chondrogenic marker genes, such as aggrecan and collagen type II $\alpha 1$, was analyzed by reverse transcription-polymerase chain reaction (RT-PCR). Briefly, total RNA was isolated from SMSCs with nucleospin total RNA isolation kit (Takara, Shiga, Japan) and complementary DNA (cDNA) was synthesized from $1 \mu \mathrm{g}$ RNA using PrimeScript $1^{\text {st }}$ strand cDNA synthesis kit (Takara), following the manufacturers' instructions. Glyceraldehyde 3phosphate dehydrogenase (GAPDH) was used as a reference gene and the primer sequences are presented in Table 1. PCR reactions were performed in a thermal cycler (Eppendorf, Hamburg, Germany) with the following conditions: $30 \mathrm{sec}$ at $95{ }^{0} \mathrm{C}, 30 \mathrm{sec}$ at $58{ }^{0} \mathrm{C}$, and $90 \mathrm{sec}$ at $72{ }^{0} \mathrm{C}$ for 30 cycles, followed by a final 10 min extension at $72^{\circ} \mathrm{C}$. The PCR products were separated in $1.5 \%$ agarose gel. Average intensity of band was analyzed with the Gel DocTM XR1 (BioRad, CA).

\section{Statistical analysis}

All data are presented as the mean \pm standard deviation. Comparison of values was carried out by one-way and two-way analysis of variance (ANOVA) with Tukey's multiple comparison test using GraphPad Prism 8.0 software (GraphPad, CA, USA). The level of significance was considered at $\mathrm{P}<0.05$.

\section{RESULTS}

Establishment of primary culture, morphology and clonal propagation of SMSCs

SMSCs were successfully established by plasticadherent culture method. Initially, the cells exhibited small, spindle shape, but later they formed a monolayer by showing fibroblast-like morphology (Figure 1A-B). SMSCs under primary culture conditions had the ability to form clusters. Cells reached $90 \%$ confluence by day 15 and were subjected for subpassaging after trypsinization. Representative images of clonal propagation of SMSCs are presented in Figure 1 C-D. A low seeding density of cells at P1 showed their proper attachment on day 3 and active proliferation by day 7 of culture. Single cell colonies were found around day 20. 


\section{Table 1: Details of chondrogenic genes and primer sequences}

\begin{tabular}{|c|c|c|c|c|}
\hline $\begin{array}{l}\text { Sl. } \\
\text { No. }\end{array}$ & Gene name & Sequence $\left(5^{\prime}-3^{\prime}\right)$ & Size (bp) & Accession No. \\
\hline 1 & Aggrecan & $\begin{array}{l}\text { F: AGTCACACCTGAGCAGCATC } \\
\text { R: AGTTCTCAAATTGCATGGGGTGTC }\end{array}$ & 147 & NM_001135.3 \\
\hline 2 & Collagen II $\alpha \mathrm{I}$ & $\begin{array}{l}\text { F: GGATGGCTGCACGAAACATACCGG } \\
\text { R:CAAGAAGCAGACCGGCCCTATG }\end{array}$ & 157 & NM_001844.4 \\
\hline 3 & GAPDH & $\begin{array}{l}\text { F: AATGGGCAGCCGTTAGGAAA } \\
\text { R: GCGCCCAATACGACCAAATC }\end{array}$ & 151 & NM_001256799.2 \\
\hline
\end{tabular}
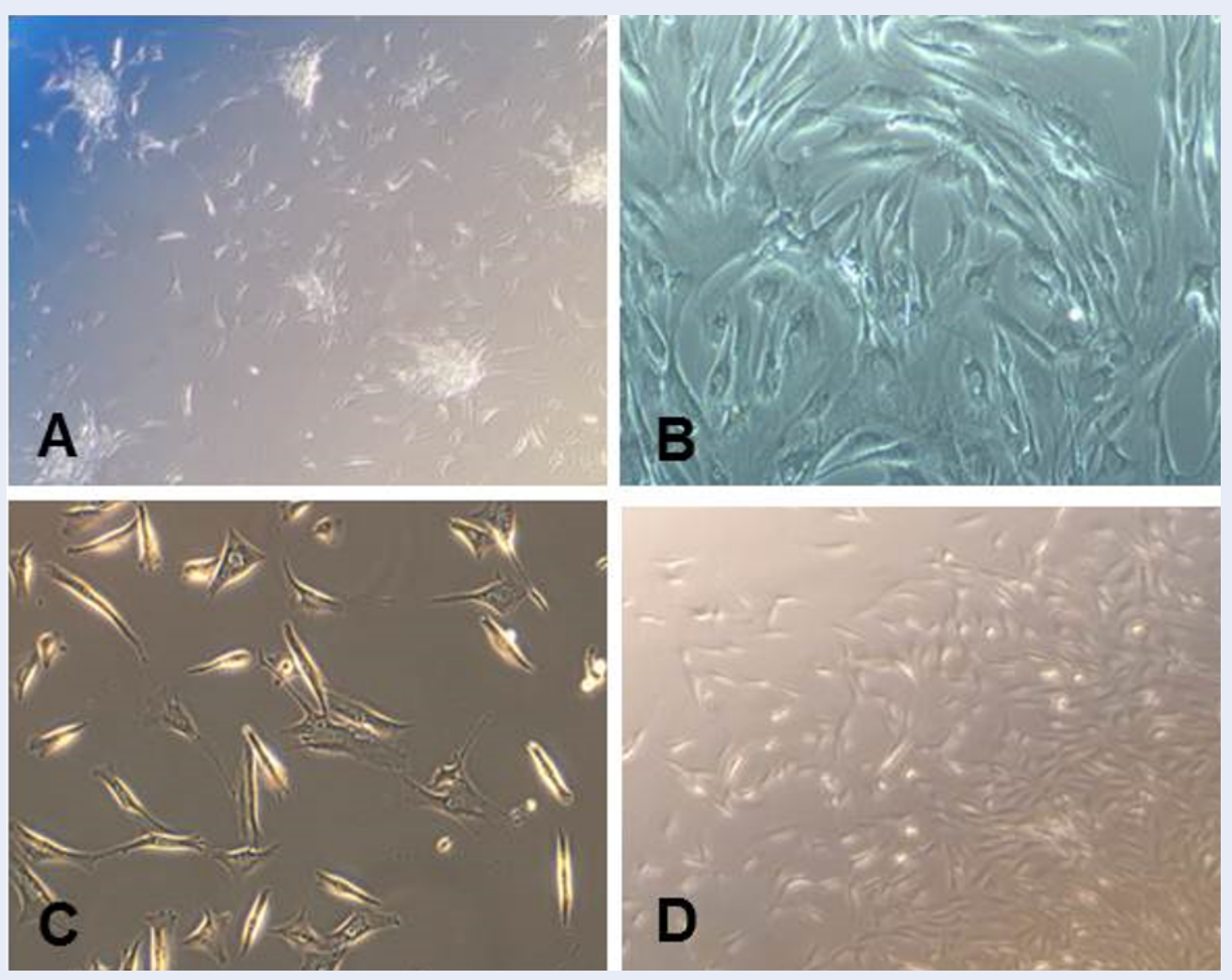

Figure 1: Morphology and clonal propagation of SMSCs. A. Plastic adherence with spindle-shape and formation of clusters by SMSCs under primary culture conditions. B. Cells showing characteristic fibroblast-like morphology at passage 3. C. SMSCs seeded at low density for clonal propagation on day 7. D. Formation of clonal clusters by SMSCs on day 20 of culture. Images A, C, D: 10x and B: 20x magnification $(n=3)$.

\section{Viability of SMSCs}

The results of percentage viability of SMSCs (SMSCs1,2 \& 3) from P0 to P4 are presented in Figure 2 A. Viability at every passage of SMSCs was determined by trypan blue staining. At $\mathrm{P} 0$, the viability ranged between 81 and $88 \%$. However, from P1 to P4, the viability of all SMSCs was found to be more than $98 \%$. Further, there were no significant $(p>0.05)$ differences observed between the passages and cell lines, except at P0, where the values were lower and found significantly different $(\mathrm{P}<0.05)$ compared to later passages.

\section{Proliferation and population doubling time (PDT) of SMSCs}

Proliferation rate of SMSCs (SMSCs-1, 2, \& 3) is presented graphically in Figure 2 B. With uniform initial seeding densities (5,000 cells per well), cell counts were obtained at every 3 days of culture up to day 12 (performed in triplicate). A significant increase 

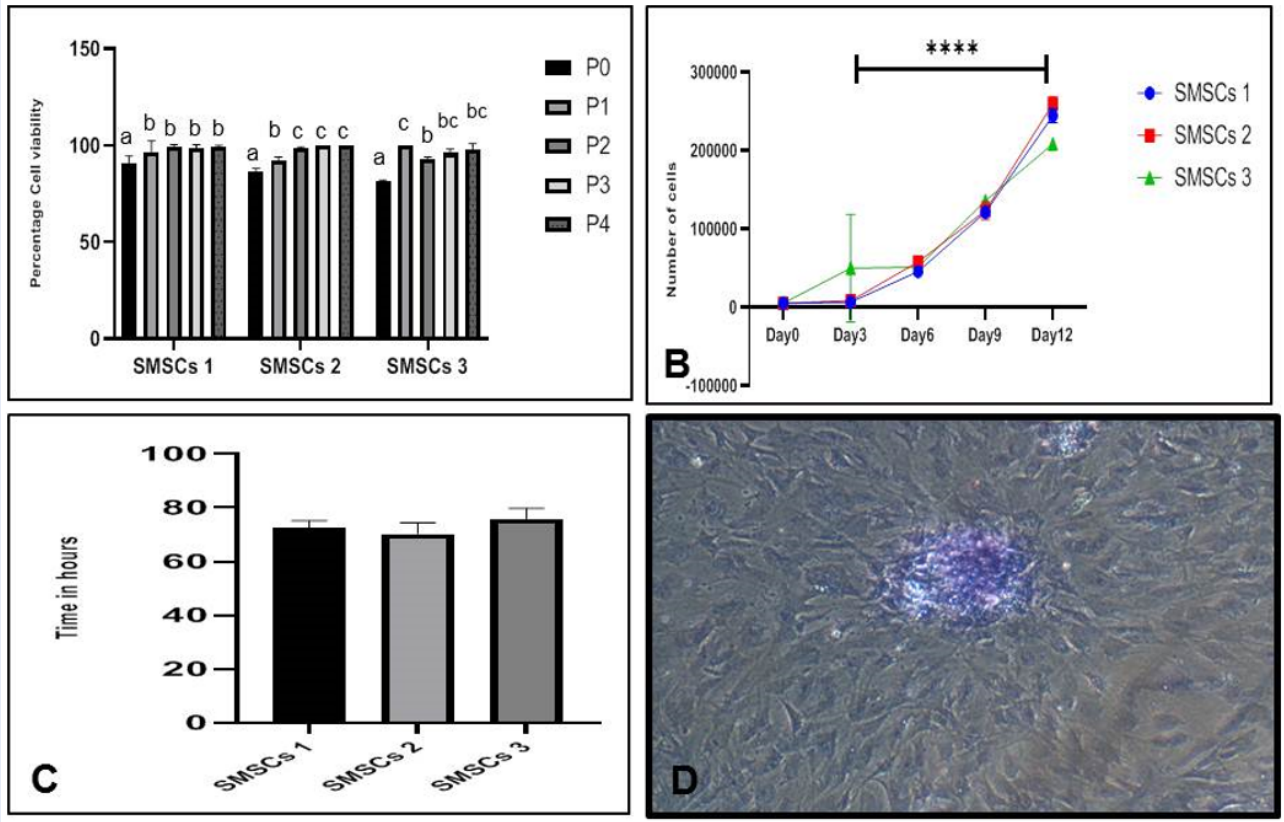

Figure 2: Basic cellular properties of SMSCs in three different cell lines. A. Cell viability of SMSCs was observed more than $98 \%$ in every passage from P0 to P4. B. All three cell lines were highly proliferative log phase of proliferation was observed from day 3 to day 12. C. 70-75 hrs Population doubling time was recorded. D. Representative image of colony forming ability of SMSCs stained with crystal violet. Image D: $4 x$ magnification $(n=3)$.

in cell number was noticed at every stage of counting $(\mathrm{P}<0.05)$. The mean proliferation counts were comparable across the three cell lines of SMSCs during expansion. Similar to other diploid cells, SMSCs grew at a rather consistent rate during early days of culture and then with a gradual increase in cell proliferation and number, and attained a peak as days of culture increased (Figure 2 B).

In support of the considerable proliferative abilities of SMSCs, the time for population doublings remained shorter and ranged between 70 and 75 hrs when examined at P3 (Figure $2 \mathrm{C}$ ). Moreover, there was no significant $(\mathrm{P}>0.05)$ difference in $\mathrm{PDT}$ observed between the cell lines.

\section{Colony-forming ability of SMSCs}

The initial growth of SMSCs in primary culture on a plastic surface was documented by the formation of single-cell-derived colonies. Later at P4, SMSCs were cultured up to 14 days in a 6 -well culture plate with a seeding density of 50 cells $/ \mathrm{cm}^{2}$, and the colonies were observed by staining with Crystal violet solution. SMSCs exhibited lesser ability to form larger colonies and decreased clonogenic potential over time. The number of colonies formed was also decreased with increased passages.

\section{Cell surface marker analysis of SMSCs}

Cell surface markers in SMSCs were analyzed by both flow cytometry and immunocytochemistry, and the representative results are presented in Figure 3 and Figure 4, respectively. MSC-specific marker expression in clonally-expanded SMSCs was quantitatively and qualitatively examined. Assays clearly demonstrated the positive expression of CD29, CD44 and CD90 as MSC-specific markers. However, there was no expression of CD34 and CD45 markers (hematopoietic lineage) in the cultured SMSCs (Figure 3). These results were further supported by the immunofluorescent expression of positive markers, but no expression of hematopoietic markers.

\section{Osteogenic differentiation of SMSCs}

Following three weeks of osteogenic induction, SMSCs displayed a characteristic osteogenic phenotype, and the accumulation of calcified mineralized matrix was evidenced by von Kossa staining (Figure 5 A). No such mineralization was visible in the uninduced (control) SMSCs.

\section{Chondrogenic differentiation of SMSCs}

The results of chondrogenic differentiation ability of SMSCs are presented in Figure 5 A. SMSCs, after 

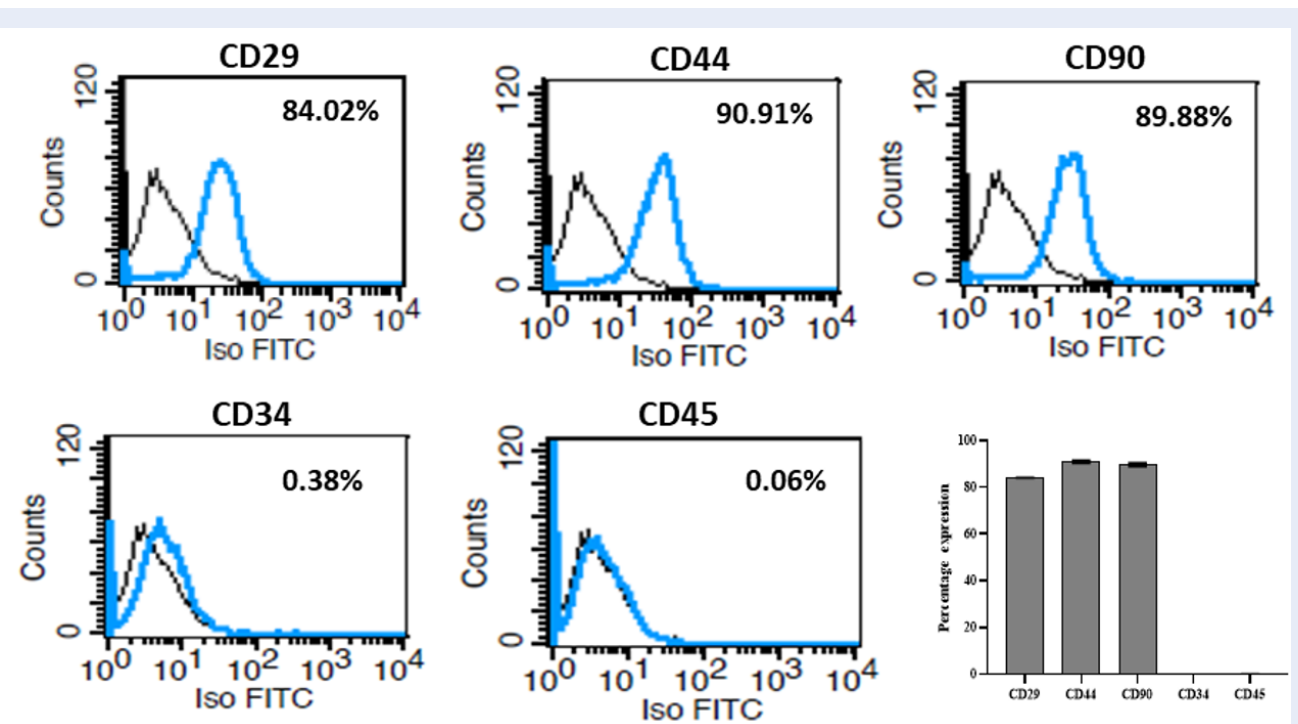

Figure 3: Representative images of flow cytometric analysis of cell surface markers in SMSCs. Cells were labeled with antibodies against CD29, CD44, CD90, CD34, and CD45 and analysed by flow cytometry in triplicates. Dark-lined histogram indicates isotype control and blue-lined histogram represent the fluorescent intensity of each marker. SMSCs were strongly positive for CD29, CD44 and CD90, and negative for CD34 and CD44 markers. $(n=3)$

three weeks of chondrogenic induction in the presence of TGF-beta, revealed the synthesis and secretion of proteoglycans and glycosaminoglycans (GAGs), as demonstrated by Alcian blue staining. In the control, SMSCs showed retention of fibroblast-like cell morphology with no chondrogenesis. In addition to cytochemical staining of chondrocytes differentiated from SMSCs, chondrogenic marker expression was assessed by RT-PCR (Figure 5 B). In control, a weaker expression of aggrecan and collagen II $\alpha 1$ was detected. However, in induced SMSCs, a prominent expression of these two chondrogenic specific markers was observed, thus confirming the production of cartilage-specific proteoglycans.

\section{Adipogenic differentiation of SMSCs}

SMSCs cultured in adipogenic induction medium showed intracellular accumulation of neutral fat globules with adipocyte phenotypic features (Figure $5 \mathrm{~A}$ ). Oil Red O staining clearly demonstrated the formation of lipid droplets prominently in cultures. However, no differentiation was observed in control SMSCs.

\section{DISCUSSION}

The present study successfully isolated SMSCs from joints with OCD, and characterized them based on their morphology, growth kinetics, clonal propagation ability, expression of MSC-specific positive and negative markers, and multilineage differentiation potential. Under in vitro culture, these cells showed plastic adherence and fibroblast-like morphology with an ability to form colonies/clusters at lower seeding density with viability of more than $90 \%$. These characteristics of SMSCs at the initial phase of culture expansion indicated the efficiency of the isolation process adopted for the synovial tissue biopsies. As previously opined, the quality of collected tissue determined the isolation success rather than the amount of biopsy processed ${ }^{12}$. Further, these observations on the morphology and early growth kinetics of SMSCs are in agreement with the findings of other studies ${ }^{6,12,13}$.

In this study, the colonies obtained from partial clonogenic assay showed greater proliferation capacity than that of cells grown at optimum cell density. Hence, these colonies were employed for further analyses. Lower seeding densities enhanced the proliferation of SMSCs with greater homogeneity, and this feature is attributed to a reduction in contact inhibition. It has been shown that SMSCs proliferate rapidly when passaged by plating the cells at low densities of $10-100$ cells $/ \mathrm{cm}^{2}{ }^{14}$. In addition, a greater clonogenicity and chondrogenic capacity of progenitor cell subsets that co-exist within the synovium has also been reported ${ }^{15}$. These results emphasized the need for establishing pure cell populations with the clinically de- 

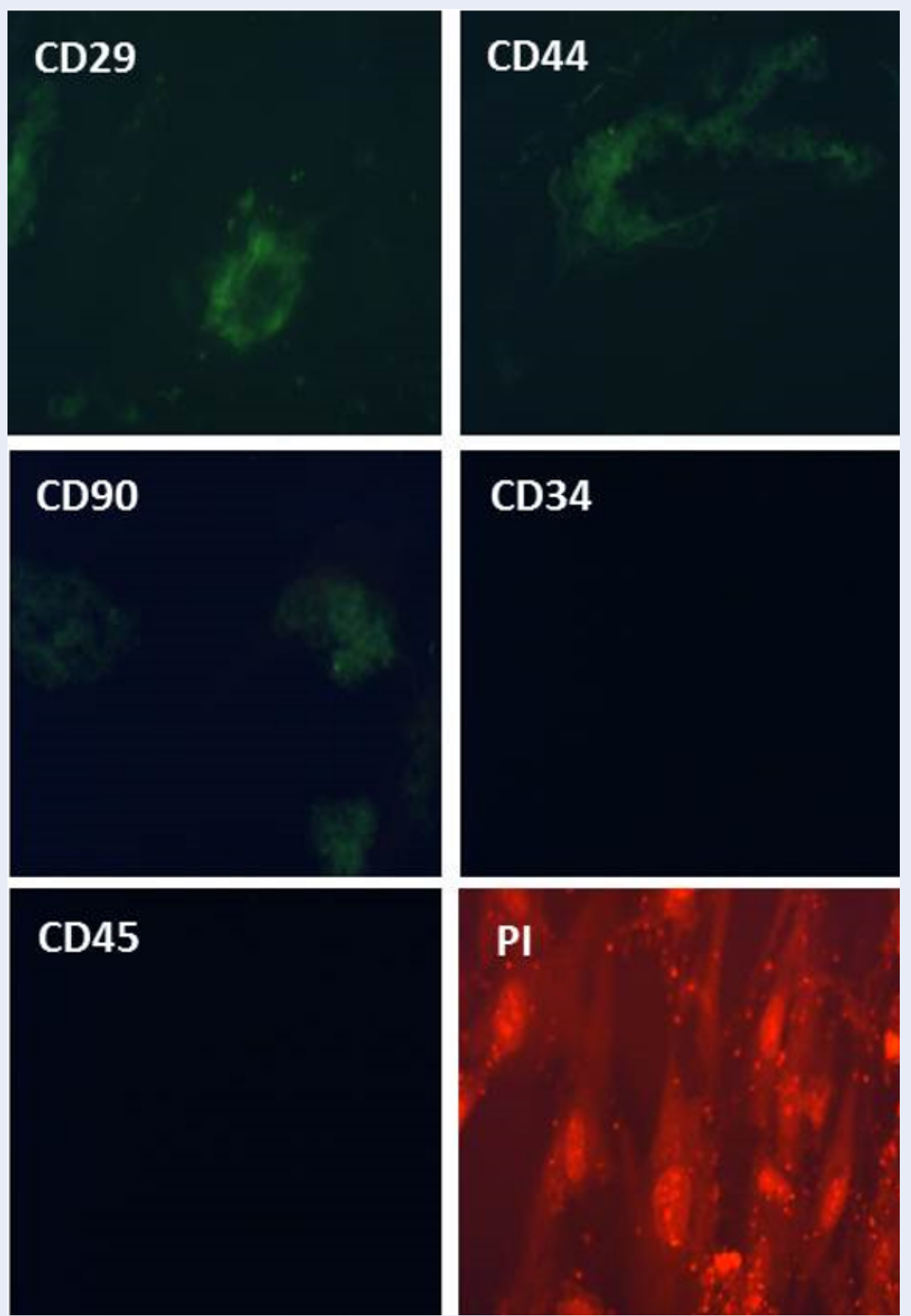

Figure 4: Immunocytochemistry analysis of cell surface markers in SMSCs. Cells were positive for the expression of CD29, CD44 and CD90 markers against FITC (fluorescein isothiocyanate) staining. There was no expression of CD34 and CD45 markers in the cultured SMSCs. Cell nucleus was counterstained with propidium iodide (PI). Representative images are shown. Images: 20x magnification. 

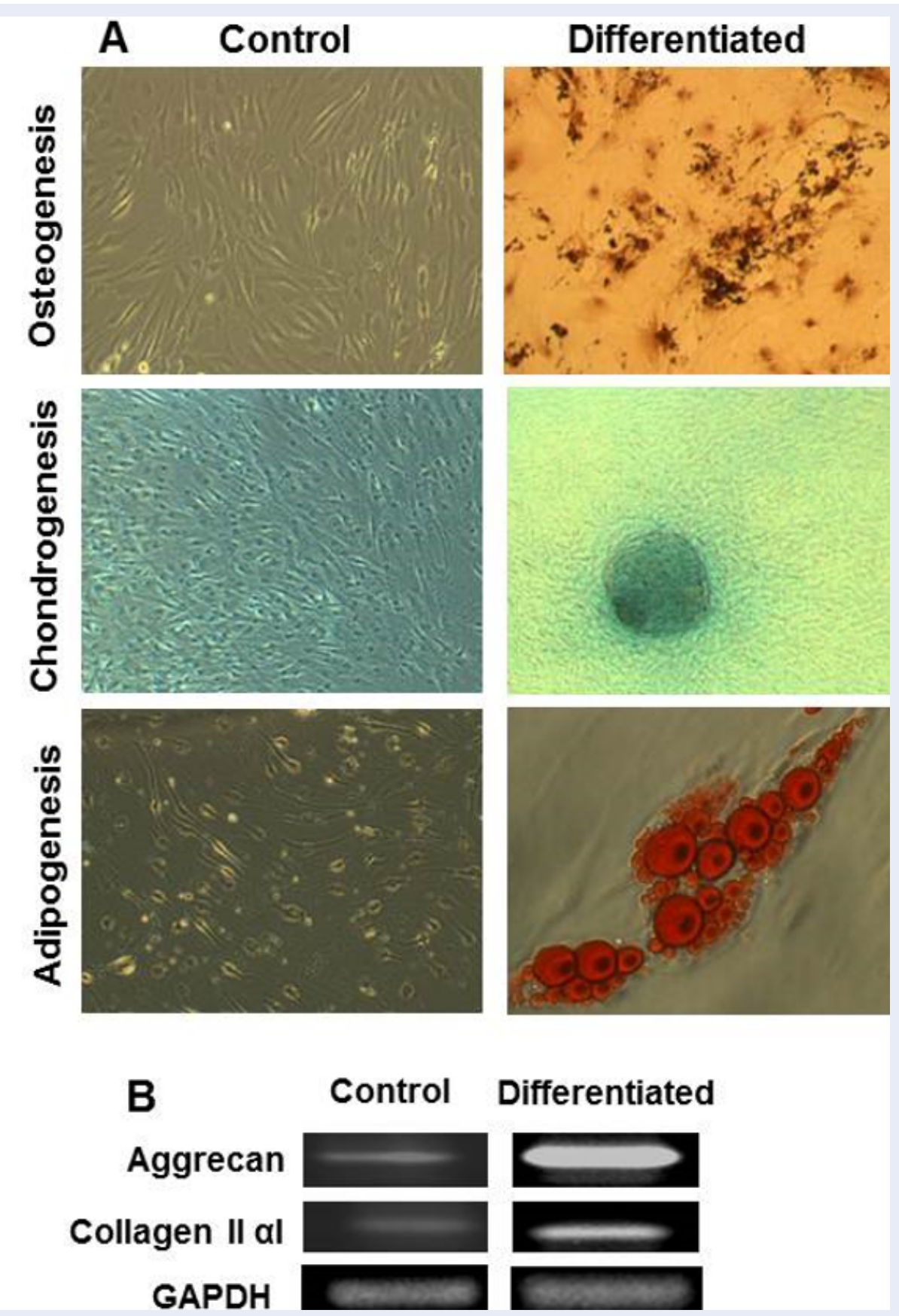

Figure 5: Multilineage differentiation potential of SMSCs at 3 weeks after induction in specific media. A. Osteogenesis was observed after the deposition of calcium nodules by von Kossa staining. Chondrogenesis was exhibited by Alcian blue staining of glycosaminoglycans. Intracellular accumulation of lipids stained by Oil red indicated the adipogenesis. In control, cells retained the fibroblast-like morphology with no differentiation. Images: 10x magnification. B. RT-PCR analysis of chondrogenic gene expression. Expression of aggrecan and collagen II $\alpha 1$ was higher in differentiated SMSCs when compared to control. GAPDH was used as a reference gene. $(n=3)$ 
sired tissue formation potentials. However, it is suggested that heterogeneity with individual clonal populations in SMSCs might lead to a variable proliferation and differentiation potential.

The clinical application of SMSCs needs the availability of a large number of functionally competent cells. In this study, SMSCs exhibited a higher proliferation rate with a shorter duration for population doublings. Replicative senescence is a normal phenomenon observed in all adult diploid cells ${ }^{16}$ and these features were not found in in vitro-expanded SMSCs, at least until passage 5. Earlier studies revealed that synovialderived MSCs maintained linear growth curve and possessed greater proliferation ${ }^{17,18}$. It is noteworthy to mention that proliferation and population doublings are largely dependent on the age and condition of the donor, and also the yield of cells at primary culture $^{12}$. Although our results are comparable with earlier reports, a weaker clonogenic capacity at later passages of SMSCs needs to be studied further as it directly indicates the modulation of cell behavior and proliferative ability.

Due to unavailability of specific criteria that define the multipotent SMSCs, these cells are usually assessed in functional terms based on phenotypical marker expression and capacity for multilineage differentiation. In this study, phenotypic characterization of SMSCs using different MSC-specific markers, such as CD29, CD44, CD90, CD34 and CD45, showed that they were of mesenchymal origin with typical expression and did not include hematopoietic cells. The expression of membrane-associated proteins, integrins and adhesion molecules provides strong evidence for their stemness characteristics ${ }^{19}$. The observations correspond with earlier reports that describe SMSCs which are positive for CD29, CD44 and CD90, and negative for CD34 and CD45 (as hematopoietic markers) ${ }^{12,13}$. In vitro-cultured SMSCs showed more inclination towards chondrogenic differentiation capacity when compared to osteogenic ability. Moreover, the cells also possessed adipogenic differentiation capacity under specific culture conditions. Although the ability for multilineage differentiation is a defining feature of MSCs, it is observed that cells from different tissue sources show predisposition in their differentiation pattern as noticed in this study with SMSCs for chondrogenesis. Chondrocyte-specific gene expression, such as aggrecan and collagen II $\alpha 1$, further emphasized that SMSCs seem to be specialized, at least in part, towards chondrogenic lineage due to their tissue source. In an earlier study, the detection of type II collagen protein by immunostaining and of collagen types IIA, IIB, IX, and X messenger RNA (mRNA) confirmed the cartilage phenotype of the tissue generated in vitro ${ }^{6}$. In addition, MSCs isolated from various intraarticular tissues including synovium showed gene expression profiles closely resembling each other ${ }^{7}$. However, an impaired chondrogenesis and enhanced osteogenesis have been evident in MSCs derived from osteoarthritis patients ${ }^{20}$. It has also been reported that dedifferentiated chondrocytes from articular cartilage of healthy and osteoarthritic donors have been shown to exhibit MSC characteristics. However, the reported rates of tripotent cloned cell populations arising from them varied from $10 \%$ to $30 \%{ }^{21,22}$. However, we did not observe any diminished chondrogenic potential of SMSCs derived from the joints of OCD patients.

\section{CONCLUSIONS}

Collectively, it is concluded that synovial tissue is an important source of MSCs because of its proximity towards articular cartilage. Given that the condition of OCD may not affect the potency of SMSCs, synovium-derived MSCs could serve as a good autologous source for cartilage tissue regeneration.

\section{ABBREVIATIONS}

ANOVA: Analysis of variance

DMEM: Dulbecco's modified essential medium

DPBS: Dulbecco's phosphate buffered saline

FBS: Fetal bovine serum

GAGs: Glycosaminoglycans

GAPDH: Glyceraldehyde 3-phosphate dehydrogenase

MSCs: Mesenchymal stem cells

OCD: Osteochondritis dissecans

RT-PCR: Reverse transcription-polymerase chain reaction

SMSCs: Synovial-derived mesenchymal stem cells

\section{ACKNOWLEDGMENTS}

The authors gratefully acknowledge the research support from Nitte (Deemed to be University).

\section{AUTHOR'S CONTRIBUTIONS}

All authors made substantial contributions to conception and design, acquisition of data, or analysis and interpretation of data; took part in drafting the article or revising it critically for important intellectual content; gave final approval of the version to be published and consent to be accountable for all aspects of the work. All authors read and approved the final manuscript. 


\section{FUNDING}

This project was funded by Nitte (Deemed to be University) Faculty Research grant (NUFR2-067) from Nitte (Deemed to be University).

\section{AVAILABILITY OF DATA AND MATERIALS}

Data and materials used and/or analysed during the current study are available from the corresponding author on reasionable request.

\section{ETHICS APPROVAL AND CONSENT TO PARTICIPATE}

The study obtained prior permission from the Institutional Ethics Committee (No. NU/CEC/2017/0182) and Institutional Committee for Stem Cell Research (No. NU/ICSCR/2016-17/002A/P10).

\section{CONSENT FOR PUBLICATION}

Not applicable.

\section{COMPETING INTERESTS}

The authors declare that they have no competing interests.

\section{REFERENCES}

1. Schenck JRC, Goodnight JM. Current concept reviewosteochondritis dissecans. Journal of Bone Joint Surgery. 1996;78(3):439-456. Available from: https: //doi.org/10.2106/00004623-199603000-00018.

2. Kocher MS, Tucker R, Ganley TJ, Flynn JM. Management of osteochondritis dissecans of the knee: current concepts review. American Journal of Sports Medicine. 2006;34(7):11811191. PMID: 16794036. Available from: https://doi.org/10. 1177/0363546506290127.

3. Dijk VCN, Reilingh ML, Zengerink M, Bergen VCJ. Osteochondral defects in the ankle: why painful? Knee Surgery Sports Trauma Arthroscopy. 2010;18(5):570-580. PMID: 20151110. Available from: https://doi.org/10.1007/s00167-010-1064-x.

4. Heijink A, Gomoll AH, Madry $H$, Drobnič $M$, Filardo $G$ et al. Biomechanical considerations in the pathogenesis of osteoarthritis of the knee. Knee Surgery Sports Trauma Arthroscopy. 2012;20(3):423-435. PMID: 22173730. Available from: https://doi.org/10.1007/s00167-011-1818-0.

5. Ruch DS. The arthroscopic management of osteochondritis dissecans of the adolescent elbow. Arthroscopy;14(8):797803. Available from: https://doi.org/10.1016/S0749-8063(98) 70013-1.

6. Bari C, Dell'Accio F, Tylzanowski P, Luyten FP. Multipotent mesenchymal stem cells from adult human synovial membrane. Arthritis Rheumatology. 2001;44(8):1928-1942. Available from: https://doi.org/10.1002/1529-0131(200108)44:8<1928:: AID-ART331>3.0.CO;2-P.

7. Segawa $Y$, Muneta T, Makino H, Nimura A, Mochizuki T et al. Mesenchymal stem cells derived from synovium, meniscus, anterior cruciate ligament, and articular chondrocytes share similar gene expression profiles. Journal of Orthopedic Research. 2009;27(4):435-441. PMID: 18973232. Available from: https://doi.org/10.1002/jor.20786.

8. To K, Zhang B, Romain K, Mak C, Khan W. Synovium-derived mesenchymal stem cell transplantation in cartilage regeneration: A PRISMA review of in vivo studies. Frontiers in Bioengi- neering Biotechnology. 2019;7:314. PMID: 31803726. Available from: https://doi.org/10.3389/fbioe.2019.00314.

9. Colombini A, Perucca Orfei C, Kouroupis D, Ragni E, De Luca P et al. Mesenchymal stem cells in the treatment of articular cartilage degeneration: New biological insights for an old-timer cell. Cytotherapy. 2019;21(12):1179-1197. PMID: 31784241. Available from: https://doi.org/10.1016/j.jcyt.2019.10.004.

10. Song JS, Hong KT, Kim NM, Jung JY, Park HS et al. Allogenic umbilical cord blood-derived mesenchymal stem cells implantation for the treatment of juvenile osteochondritis dissecans of the knee. Journal of Clinical Orthopedics and Trauma. 2019;10(1):S20-S25. PMID: 31700204. Available from: https: //doi.org/10.1016/j.jcot.2019.03.025.

11. Hori J, Deie $M$, Kbayashi $T$, Yasunaga $Y$, Kawameta $S$ et al. Articular cartilage repair using an intra-articular magnet and synovium derived cells. Journal of Orthopedic Research. 2011;29(4):531-538. PMID: 21337393. Available from: https: //doi.org/10.1002/jor.21267.

12. Ferro T, Santhagunam A, Madeira C, Salgueiro JB, da Silva $\mathrm{CL}$ et al. Successful isolation and ex vivo expansion of human mesenchymal stem/stromal cells obtained from different synovial tissue-derived (biopsy) samples. J Cell Physiology. 2019;234(4):3973-3984. PMID: 30146686. Available from: https://doi.org/10.1002/jcp.27202.

13. Fernandes TL, Kimura HA, Pinheiro CCG, Shimomura K, Nakamura $\mathrm{N}$ et al. Human synovial mesenchymal stem cells good manufacturing practices for articular cartilage regeneration. Tissue Engineering Part C Methods. 2018;24(12):709-716. PMID: 30412046. Available from: https://doi.org/10.1089/ten. tec.2018.0219.

14. Camilleri ET, Gustafson MP, Dudakovic A, Riester SM, Garces CG et al. Identification and validation of multiple cell surface markers of clinical-grade adipose-derived mesenchyma stromal cells as novel release criteria for good manufacturing practice-compliant production. Stem Cell Research and Therapy. 2016;7(1):107. PMID: 27515308. Available from: https://doi.org/10.1186/s13287-016-0370-8.

15. Karystinou A, Dell'Accio F, Kurth TB, Wackerhage $H$, Khan IM et al. Distinct mesenchymal progenitor cell subsets in the adult human synovium. Rheumatology. 2009;48(9):10571064. PMID: 19605375. Available from: https://doi.org/10. 1093/rheumatology/kep192.

16. Cristofalo VJ, Allen RG, Pignolo RJ, Martin BG, Beck JC. Relationship between donor age and the replicative lifespan of human cells in culture: a reevaluation. Proceedings of $\mathrm{Na}$ tional Academy of Sciences, U S A. 1998;95(18):10614-10619. PMID: 9724752. Available from: https://doi.org/10.1073/pnas. 95.18.10614.

17. Kubosch EJ, Lang G, Furst D, Kubosch D, Izadpanah K et al. The potential for synovium-derived stem cells in cartilage repair. Current Stem Cell Research. 2018;13(3):174184. PMID: 28969580. Available from: https://doi.org/10.2174/ 1574888 X12666171002111026.

18. Sekiya I, Muneta T, Horie M, Koga H. Arthroscopic transplantation of synovial stem cells improves clinical outcomes in knees with cartilage defects. Clinical Orthopedic Related Research. 2015;473(7):2316-2326. PMID: 25925939. Available from: https://doi.org/10.1007/s11999-015-4324-8.

19. Dominici ML, Le Blanc K, Mueller I, Slaper-Cortenbach I, Marini FC et al. Minimal criteria for defining multipotent mesenchymal stromal cells. The International Society for Cellular Therapy position statement Cytotherapy. 2006;8(4):315-317. PMID: 16923606. Available from: https://doi.org/10.1080/ 14653240600855905.

20. Wyles CC, Houdek MT, Behfar A, Sierra RJ. Mesenchymal stem cell therapy for osteoarthritis: current perspectives. Stem Cells Cloning. 2015;8:117-124. PMID: 26357483. Available from: https://doi.org/10.2147/SCCAA.S68073.

21. Boeuf S, Richter W. Chondrogenesis of mesenchymal stem cells: role of tissue source and inducing factors. Stem Cell Research and Therapy. 2010;1(4):31. PMID: 20959030. Available from: https://doi.org/10.1186/scrt31. 
22. Barbero A, Ploegert S, Heberer M, Martin I. Plasticity of clonal populations of dedifferentiated adult human articular chon- drocytes. Arthritis Rheumatism. 2003;48(5):1315-1325. PMID: 12746904. Available from: https://doi.org/10.1002/art.10950. 